\title{
BMJ Open Opioid-sparing effects of medical cannabis or cannabinoids for chronic pain: a systematic review and meta-analysis of randomised and observational studies
}

Atefeh Noori, ${ }^{1,2}$ Anna Miroshnychenko, ${ }^{1}$ Yaadwinder Shergill, ${ }^{1}$ Vahid Ashoorion, ${ }^{1}$ Yasir Rehman, ${ }^{1}$ Rachel J Couban, ${ }^{2}$ D Norman Buckley, ${ }^{3}$ Lehana Thabane (1) , ${ }^{1}$ Mohit Bhandari, ${ }^{1,4}$ Gordon H Guyatt, ${ }^{1}$ Thomas Agoritsas, ${ }^{1,5}$ Jason W Busse (1) 1,3,6,7

To cite: Noori A,

Miroshnychenko A, Shergill Y, et al. Opioid-sparing effects of medical cannabis or cannabinoids for chronic pain: a systematic review and metaanalysis of randomised and observational studies. BMJ Open 2021;11:e047717. doi:10.1136/ bmjopen-2020-047717

- Prepublication history and supplemental material for this paper is available online. To view these files, please visit the journal online (http://dx.doi. org/10.1136/bmjopen-2020047717).

Received 07 December 2020 Accepted 05 July 2021

Check for updates

(C) Author(s) (or their employer(s)) 2021. Re-use permitted under CC BY-NC. No commercial re-use. See rights and permissions. Published by BMJ.

For numbered affiliations see end of article.

Correspondence to Professor Jason W Busse; bussejw@mcmaster.ca

\section{ABSTRACT}

Objective To assess the efficacy and harms of adding medical cannabis to prescription opioids among people living with chronic pain.

Design Systematic review.

Data sources CENTRAL, EMBASE and MEDLINE.

Main outcomes and measures Opioid dose reduction, pain relief, sleep disturbance, physical and emotional functioning and adverse events.

Study selection criteria and methods We included studies that enrolled patients with chronic pain receiving prescription opioids and explored the impact of adding medical cannabis. We used Grading of Recommendations Assessment, Development and Evaluation to assess the certainty of evidence for each outcome.

Results Eligible studies included five randomised trials (all enrolling chronic cancer-pain patients) and 12 observational studies. All randomised trials instructed participants to maintain their opioid dose, which resulted in a very low certainty evidence that adding cannabis has little or no impact on opioid use (weighted mean difference (WMD) -3.4 milligram morphine equivalent (MME); 95\% $\mathrm{Cl}(\mathrm{Cl})-12.7$ to 5.8). Randomised trials provided high certainty evidence that cannabis addition had little or no effect on pain relief (WMD $-0.18 \mathrm{~cm} ; 95 \% \mathrm{Cl}-0.38$ to 0.02 ; on a $10 \mathrm{~cm}$ Visual Analogue Scale (VAS) for pain) or sleep disturbance (WMD $-0.22 \mathrm{~cm} ; 95 \% \mathrm{Cl}-0.4$ to -0.06 ; on a $10 \mathrm{~cm}$ VAS for sleep disturbance; minimally important difference is $1 \mathrm{~cm}$ ) among chronic cancer pain patients. Addition of cannabis likely increases nausea (relative risk (RR) 1.43; 95\% Cl 1.04 to 1.96; risk difference (RD) 4\%, $95 \% \mathrm{Cl} 0 \%$ to $7 \%$ ) and vomiting (RR $1.5 ; 95 \% \mathrm{Cl} 1.01$ to 2.24; RD 3\%; 95\% Cl 0\% to 6\%) (both moderate certainty) and may have no effect on constipation (RR $0.85 ; 95 \% \mathrm{Cl}$ 0.54 to $1.35 ; \mathrm{RD}-1 \% ; 95 \% \mathrm{Cl}-4 \%$ to $2 \%$ ) (low certainty). Eight observational studies provided very low certainty evidence that adding cannabis reduced opioid use (WMD $-22.5 \mathrm{MME} ; 95 \% \mathrm{Cl}-43.06$ to -1.97 ).

Conclusion Opioid-sparing effects of medical cannabis for chronic pain remain uncertain due to very low certainty evidence.

PROSPERO registration number CRD42018091098.

\section{Strengths and limitations of this study}

- This is the first meta-analysis to pool the results of randomised controlled trials and observational studies exploring the opioid-sparing effects of medical cannabis among people living with chronic pain.

- We conducted a comprehensive search for eligible studies, appraised the risk of bias of included studies and evaluated the certainty of evidence using the Grading of Recommendations Assessment, Development and Evaluation approach.

- Most observational studies incorporated inadequate adjustment for confounding, and all randomised trials, despite reporting this outcome, were not designed to address the effect of medical cannabis on opioid use.

\section{INTRODUCTION}

Chronic pain affects approximately one in five adults and is a common reason for seeking medical care. ${ }^{2}$ Opioids are commonly prescribed for this condition, particularly in North America; ${ }^{3}$ however, they only provide benefit to a minority of patients. A 2018 systematic review of 96 trials found high certainty evidence that, versus placebo, opioids provide important pain relief $(\geq 1 \mathrm{~cm}$ improvement on a $10 \mathrm{~cm}$ Visual Analogue Scale (VAS) for pain) to $12 \%$ of patients for whom they are prescribed. ${ }^{4}$ Moreover, opioids are associated with harms such as overdose and death, ${ }^{56}$ which are dose dependent. ${ }^{7-10}$ As a result, there is considerable interest in therapies that may allow patients with chronic pain using opioid therapy to reduce their opioid intake.

One promising approach is adding cannabis therapy, which low certainty evidence suggests may be similarly effective to opioids for reducing pain and improving physical functioning among people living 
with chronic pain. ${ }^{4}$ Experimental studies have shown that opioids and cannabis have similar signal transduction systems, ${ }^{11}$ and observational studies in the USA demonstrated that the rates of opioid-related mortality reduced after cannabis was legalised. ${ }^{12-14}$ Between $64 \%$ and $77 \%$ of patients with chronic pain responding to cross-sectional surveys reported a reduction in long-term opioid use after adding medical cannabis to their treatment. ${ }^{15}{ }^{16} \mathrm{~A}$ 2017 systematic review concluded that preclinical studies provided robust evidence for the opioid-sparing effects of cannabis. ${ }^{17}$ To clarify the issue, we undertook a systematic review of randomised controlled trials (RCT) and observational studies to explore the impact of adding medical cannabis on opioid dose, other patient-important outcomes and related harms in patients with chronic pain using prescribed opioid therapy.

This systematic review is part of the BMJ Rapid Recommendations project, a collaborative effort from the MAGIC Evidence Ecosystem Foundation (www.magicevidnece.org) and BMJ. This systematic review informed a parallel guideline published on BMJ.com ${ }^{18}$ and MAGICapp (https://app.magicapp.org/\#/guideline/ jMMYPj).

\section{METHODS}

We followed standards for Meta-analysis Of Observational Studies in Epidemiology ${ }^{19}$ and Preferred Reporting Items for Systematic Reviews and Meta-Analyses guidelines. ${ }^{20}$

\section{Eligibility criteria}

We included RCTs and observational studies, including cohort studies and case-control studies, in any language, that explored the impact of adding medical cannabis (ie, phytocannabinoids, endocannabinoids or synthetic cannabinoids) on the use of prescription opioids among people living with chronic pain. We defined pain as chronic if patients reported that symptoms had persisted for $\geq 3$ months. ${ }^{21}$ We excluded editorials, letters to the editor, preclinical studies, conference abstracts, case reports, case series, cross-sectional studies and studies with less than 2 weeks follow-up. We also excluded studies of recreational cannabis use as these products typically contain much higher amounts of the psychotropic cannabinoid tetrahydrocannabinol (THC) than would be administered for therapeutic purposes. ${ }^{22}{ }^{23}$ We classified observational study designs according to recommendations by the Cochrane Observational Studies Methods Group. $^{24}$

\section{Literature search and study selection}

We searched the Cochrane Central Register of Controlled Trials (CENTRAL), EMBASE and MEDLINE from inception to March 2020 with no restriction on language of publication. An experienced medical librarian (RJC) developed our database-specific search strategies (online supplemental appendix A). We also searched the ClinicalTrials.gov registry to identify ongoing trials, and reference lists of all eligible studies and related systematic reviews for additional eligible studies. Two teams of paired reviewers independently screened titles, abstracts and full-text studies for eligibility using online systematic review software (Rayyan QCRI, Qatar Computing Research Institute). Reviewers resolved disagreements through discussion.

\section{Data collection}

Using standardised forms and a detailed instruction manual, pairs of reviewers independently abstracted data from each eligible study, including study and patient characteristics, and details of treatment (eg, dose, formulation and duration of cannabis add-on therapy). Our primary outcome was opioid dose. We also captured all patient-important outcomes, as guided by the Initiative on Methods, Measurement, and Pain Assessment in Clinical Trials, ${ }^{25}$ including pain relief, sleep disturbance, physical and emotional functioning. Regarding adverse events, we focused on vomiting, nausea and constipation as a systematic review of values and preferences ${ }^{26}$ demonstrated that patients living with chronic pain experience gastrointestinal complaints as the most important opioidinduced adverse events. We contacted authors to obtain unpublished data.

\section{Risk of bias assessment}

Following training and calibration exercises two independent reviewers used a modified Cochrane risk of bias tooll $^{2728}$ to assess the risk of bias among eligible RCTs according to the following domains: allocation concealment, blinding of participants, study personnel, outcome assessors and data analyst, and lost to follow-up ( $\geq 20 \%$ missing data were assigned high risk of bias). Response options for each item were 'definitely or probably yes' (assigned a low risk of bias) and 'definitely or probably no' (assigned a high risk of bias) (online supplemental table 1). We used criteria suggested by the CLARITY group $^{29}$ to assess the risk of bias of observational studies including selection bias, confidence that all patients had the condition of interest, control for confounding variables, validity of outcome assessment(s), and infrequent missing data $(<20 \%)$ (details available at www.evidencepartners.com/resources/methodological-resources/). (online supplemental tables 2-3).

\section{Data analysis}

We calculated inter-rater agreement regarding the eligibility of full-text studies using an adjusted kappa ( $\mathrm{K}$ ) statistic. $^{30}$ We conducted separate analyses for RCTs and observational studies. All continuous measures for pain intensity and sleep disturbance were converted to a $10 \mathrm{~cm}$ VAS; the minimally important difference (MID) for both was $1 \mathrm{~cm} .{ }^{31}{ }^{32}$ All continuous outcomes that were reported by more than one study were pooled to derive the weighted mean difference (WMD) and associated 95\% CI. We pooled binary outcomes (adverse events) as relative risks (RRs) and risk differences (RDs) and their 
associated 95\% CIs. We conducted all meta-analyses with random-effects models and the DerSimonian-Laird method. ${ }^{33}$

When studies reported effects on continuous outcomes as the median and IQR, we derived the mean and $\mathrm{SD}$ using the method presented by Wan et al. ${ }^{34}$ We also converted medians to means using the approach recommended by the Cochrane Handbook as a sensitivity analysis. When authors failed to report a measure of precision associated with mean differences, we imputed the SD from eligible studies that reported these measures (online supplemental technical appendix).$^{35}$ We included each comparison reported by multiarm studies and calculated a correction factor to account for the unit of analysis error (ie, when information from a treatment arm is used more than once in the same meta-analysis). ${ }^{36}$ We explored the consistency of association between our pooled results and studies reporting the same outcome domains that were not possible to pool. We used Stata (StataCorp, Release V.15.1) for all analyses.Comparisons were two tailed using a threshold of $\mathrm{p} \leq 0.05$.

\section{Subgroup analyses and meta-regression}

We examined heterogeneity among pooled RCTs using the $\mathrm{I}^{2}$ statistic, and through visual inspection of forest plots for pooled observational data, because statistical tests of heterogeneity can be misleading when sample sizes are large and associated confidence intervals are therefore narrow. ${ }^{37}$ When we had at least two studies in each subgroup, we explored sources of heterogeneity with five prespecified subgroup hypotheses, assuming greater benefits with: (1) shorter versus longer duration of follow-up; (2) higher versus lower risk of bias; (3) enriched versus non-enriched study design; (4) chronic non-cancer versus chronic cancer-related pain and (5) higher versus lower THC content. We assumed similar directions of subgroup effects for harms, except for study design and THC content in which we expected greater harms with non-enriched trials and higher THC content. However, apart from item two (risk of bias), studies did not report sufficient data to undertake subgroup analyses.

\section{The certainty of the evidence}

We used the Grading of Recommendations Assessment, Development and Evaluation (GRADE) approach to assess the certainty of evidence on an outcome-byoutcome basis as high, moderate, low or very low. ${ }^{38}$ With GRADE, RCTs begin as high-certainty evidence, but can be rated down because of risk of bias, imprecision, inconsistency, indirectness or publication bias. We rated down for imprecision if the $95 \%$ CI associated with a pooled continuous outcome included half the MID, or if the estimate of precision associated with the RR for binary outcomes included no effect. We considered an $\mathrm{I}^{2}$ value between $75 \%$ and $100 \%$ to represent considerable inconsistency. ${ }^{39}$ We rated down the certainty of evidence for indirectness if there were important differences between our research question and the patients enrolled, intervention tested



Figure 1 Study selection process in review of opioidsparing effects of cannabis in chronic pain.

or outcomes reported among studies contributing to our meta-analyses. ${ }^{40}$

Using GRADE, observational studies begin as low certainty evidence, and while they can be rated down further for the same reasons as RCTs, they can also be rated up in the presence of a large magnitude of the effect, a dose-response gradient or consideration of plausible confounders or other biases that increase confidence in the estimated effect. ${ }^{41}$ We only reported the pooling results of observational studies when they resulted in the same or higher certainty of evidence than evidence from RCTs. When there were at least 10 studies for meta-analysis, we explored for small-study effects by visual assessment of funnel plot asymmetry and Egger's statistical test. $^{42}$

\section{Patients and public involvement}

Patients and public were not involved in this research.

\section{RESULTS}

Of 5133 records identified, we reviewed 133 articles in full text, and 18 studies reported in 17 publications proved eligible (figure 1, online supplemental appendix B); five RCTs in four publications ${ }^{43-46}$ and 13 observational studies. ${ }^{47-59}$ One study enrolled a mixed group of opioid and non-opioid users ${ }^{50}$; however, our attempts to contact the authors to acquire pain intensity data for the subgroup of patients prescribed opioids proved unsuccessful. All five RCTs ${ }^{43-46}$ and three observational studies ${ }^{51} 5455$ enrolled patients with chronic cancer-related pain; the remaining 10 observational studies explored adding 
cannabis to opioids for patients with chronic non-cancer pain (eg, chronic low back pain, fibromyalgia, painful chronic pancreatitis), ${ }^{47525357-59}$ or a mix of cancer and non-cancer pain (table 1$){ }^{48-50} 56$

Among the 18 included studies, the percentage of female participants was $48 \%$ (median of individual trials $48 \%$, IQR $43 \%-58 \%$ ), and the median of the mean age was 56.3 (IQR 51.2-59.9). Follow-up ranged from 2 to 5 weeks among RCTs, and from 4 weeks to 6.4 years for observational studies. Only one RCT ${ }^{43}$ used an enrichment design (following the open-label phase, patients with at least $15 \%$ improvement in pain were randomised to the intervention and control groups) and all RCTs advised patients to maintain stable doses of all other prescribed pain medications, including opioids, during the study period (table 1). All included RCTs, and three of the observational studies ${ }^{485152}$ administered synthetic cannabis products (ie, nabilone, dronabinol and nabiximole), five observational studies ${ }^{49} 50565859$ reported different combinations of THC:Cannabidiol (CBD) products, and six other observational studies ${ }^{4753-55} 57$ did not provide details on the type of cannabis or cannabinoids provided (table 1, online supplemental table 4). Ten studies reported receiving industry funding, ${ }^{43-46} 4951525758$ five studies ${ }^{505-56}$ reported no-industry funding and three studies ${ }^{47459}$ did not report funding information (table 1).

\section{Risk of bias of included studies}

All included RCTs reported adequate allocation concealment and blinding of patients and healthcare providers; however, three trials ${ }^{43}{ }^{45}$ were at risk of bias due to high lost to follow-up (online supplemental table 5). Each RCT specified that they employed an intention-to-treat analysis. All observational studies were at high risk of bias, typically due to lack of confidence in the assessment of exposure, non-representative samples and insufficient control for confounding (online supplemental file 6-7).

\section{Outcomes for medical cannabis add-on therapy Opioid dose reduction}

The primary limitation of RCTs was that all investigators instructed patients to not alter their dose of opioids. This represents a very serious indirectness of the findings regarding the research question, warranting rating down two levels, and was the primary reason for very low certainty evidence from the 1176 patients. ${ }^{43-45}$ Their results raised the possibility that adding medical cannabis may not be associated with a reduction in opioid use among patients living with chronic cancer pain (WMD -3.4 milligram morphine equivalent (MME); 95\% CI -12.7 to 5.9 ; table 2; online supplemental figure 1 ). There were no differences in effect based on the lost to follow-up (online supplemental figure 2); test of interaction $\mathrm{p}=0.758)$.

Very-low certainty evidence from eight observational studies (seven of which enrolled people with chronic noncancer pain $)^{4748505153-5558}$ raised the possibility that adding medical cannabis may reduce the use of opioids among patients with predominantly chronic non-cancer pain (WMD -22.5 MME; 95\% CI -43.06 to - 1.97; table 2; online supplemental figure 3). Three observational studies that could not be pooled, as they only reported opioid reduction as a percentage, also found that providing medical cannabis allowed patients to decrease their opioid dose. The first study assessed the impact of providing medical cannabis to 61 patients with chronic low back pain who were prescribed opioid therapy (median opioid dose was $21 \mathrm{mg} \mathrm{MME} /$ day) and reported that 52\% of patients (32 of 61) stopped all use of opioids at a median follow-up of 6.4 years. ${ }^{57}$ The second study ${ }^{49}$ reported that of 94 patients with chronic pain (both cancer and non-cancer pain) who began using CBD hemp extract, $53 \%$ were able to decrease their use of prescription opioids at 8 weeks. A third study ${ }^{56}$ included 600 patients with chronic pain who indicated willingness to taper their opioid dose and were administered $0.5 \mathrm{~g}$ daily of medicinal cannabis for each $10 \%$ reduction in opioid dose. After 6 months follow-up, $55 \%$ of patients reported a $30 \%$ reduction in opioid dose on average and $26 \%$ of them discontinued opioid use.

\section{Pain relief}

High-certainty evidence from five RCTs ${ }^{43-46}$ demonstrated that adding medical cannabis to opioid therapy resulted in trivial or no difference in cancer-related pain (WMD $-0.18 \mathrm{~cm}$; $95 \%$ CI -0.38 to 0.02 on the $10 \mathrm{~cm}$ VAS for pain; MID $1 \mathrm{~cm}$; table 2; online supplemental figure 4). Results did not differ depending on lost to follow-up (online supplemental figure 5 , a test of interaction $\mathrm{p}=0.623$ ). Very low certainty evidence from observational studies suggested a large decrease in pain when medical cannabis was added to opioids (online supplemental figure 6).

\section{Sleep disturbance}

Five RCTs $^{43-46}$ provided high certainty evidence that adding medical cannabis to prescription opioids results in a trivial improvement in sleep disturbance in people living with cancer-related chronic pain (WMD $-0.22 \mathrm{~cm}$; $95 \% \mathrm{CI}-0.4$ to -0.06 on the $10 \mathrm{~cm}$ VAS for sleep disturbance; MID $1 \mathrm{~cm}$; table 2; online supplemental figure 7). Results did not differ between trials reporting the low and high lost to follow-up (online supplemental figure 8, a test of interaction $\mathrm{p}=0.93$ ). Very low certainty evidence from observational studies suggested an improvement in sleep disturbance when medical cannabis was added to opioids (online supplemental table 8).

\section{Other reported outcomes}

A single $\mathrm{RCT}^{44}$ reported moderate certainty evidence that adding cannabis likely has little or no effect on emotional and physical functioning (online supplemental tables 9-10).

\section{Adverse events}

Nausea, vomiting or constipation

Four RCTs ${ }^{43-46}$ provided moderate certainty evidence that adding medical cannabis to opioid therapy likely increases the incidence of nausea (RR 1.43, 95\% CI 1.04 to 1.96; RD 


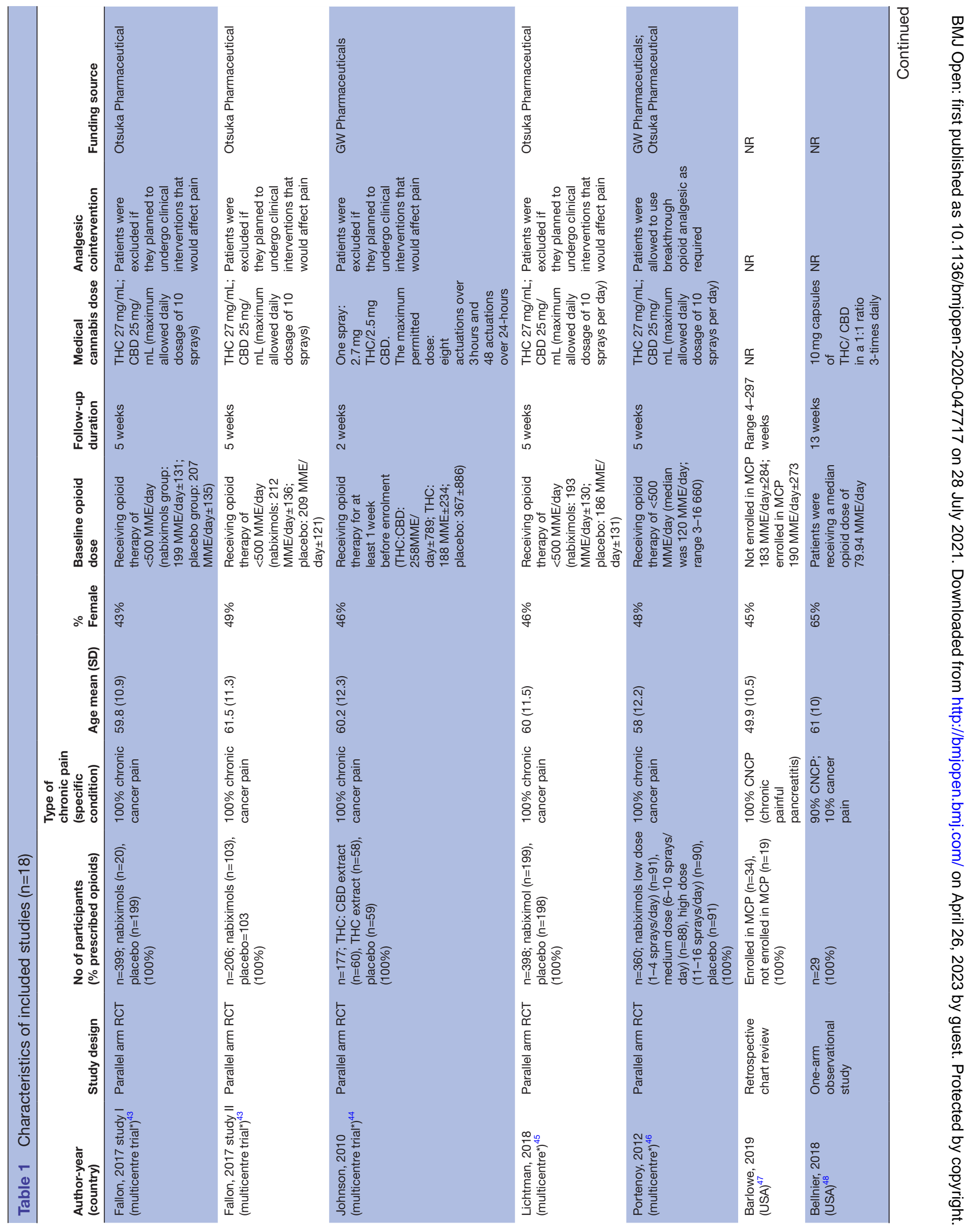






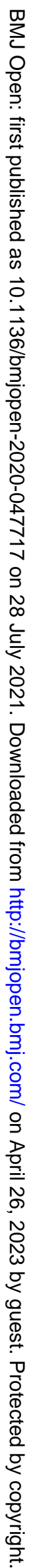




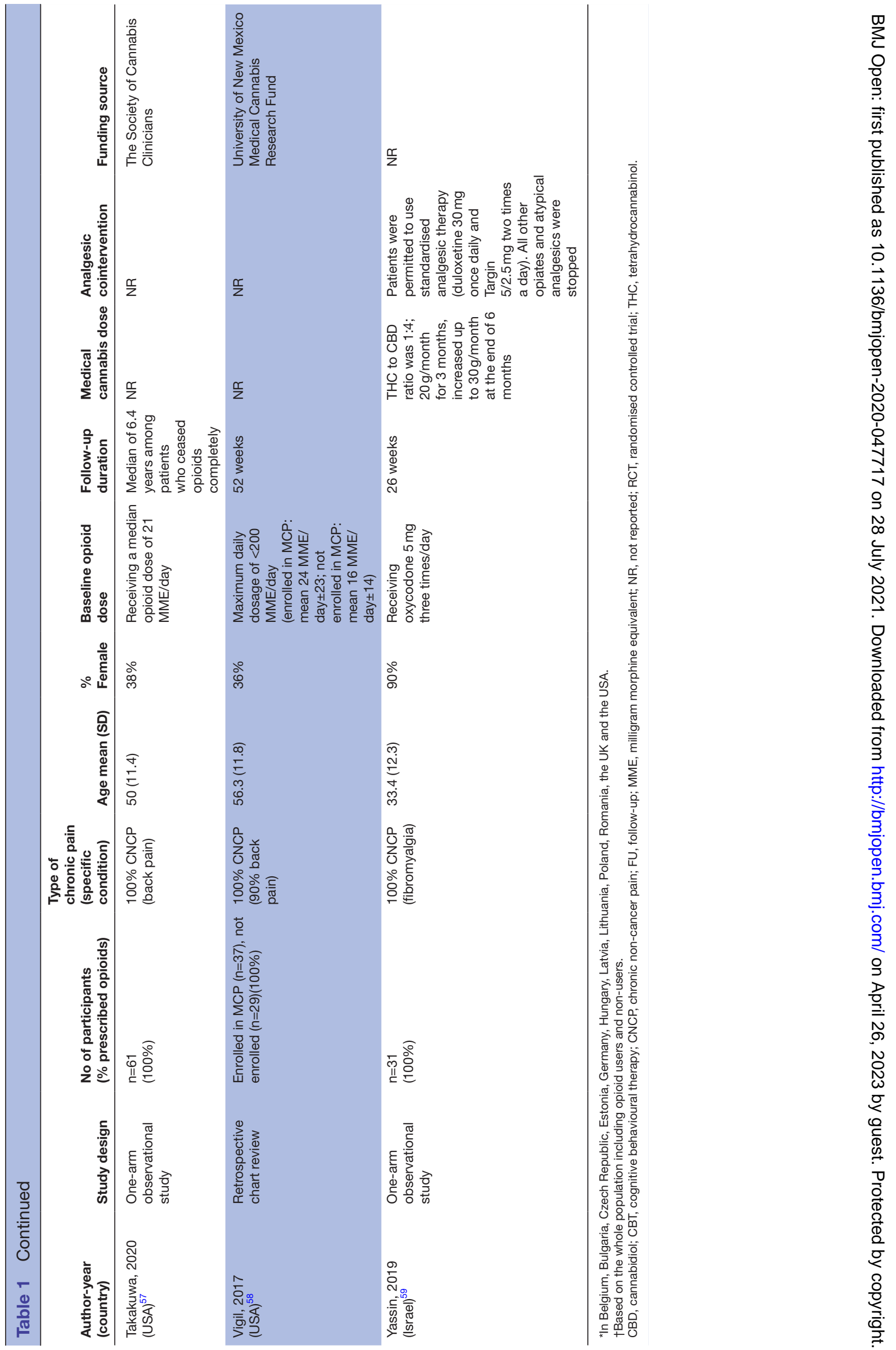





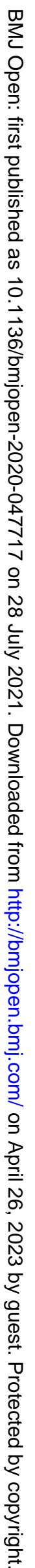


$4 \%, 95 \%$ CI $0 \%$ to $7 \%$; online supplemental figures 9-10) and vomiting (RR 1.50; 95\% CI 1.01 to 2.24 ; RD $3 \%$; $95 \%$ CI $0 \%$ to $6 \%$; online supplemental figures 11-12) in patients with cancer-related chronic pain prescribed opioid therapy. Three RCTs ${ }^{43} 4546$ provided low certainty evidence that adding medical cannabis to opioid therapy may not increase constipation (RR $0.85,95 \%$ CI 0.54 to 1.35 ; RD $-1 \%$; $95 \%$ CI $-4 \%$ to $2 \%$; online supplemental figures 13-14). Online supplemental table 11 summarises adverse events reported in observational studies.

\section{DISCUSSION}

Very low certainty evidence from randomised trials and observational studies was conflicting and leaves uncertain whether the addition of medical cannabis affects the use of prescribed opioids among people living with chronic pain. Compared with long-term opioid therapy for chronic cancer pain without medical cannabis, high certainty evidence showed that adding medical cannabis had little or no effect on pain or sleep disturbance. Results provided moderate certainty evidence that adding cannabis therapy to opioids likely increases both nausea (RR 1.43, 95\% CI 1.04 to 1.96 ) and vomiting (RR 1.50; 95\% CI 1.01 to 2.24 ) and low certainty evidence suggested no effect on constipation (RR $0.85,95 \%$ CI 0.54 to 1.35 ).

Strengths of our review include a comprehensive search for eligible randomised and observational studies, appraisal of the risk of bias among individual studies, and use of the GRADE approach to rate the certainty of evidence. Our review has limitations, primarily due to features of primary studies eligible for review, which failed to report all recommended outcomes that have been established as important for people living with chronic pain. Most observational studies incorporated inadequate adjustment for confounding. All randomised trials, despite reporting this outcome, were not designed to address the effect of medical cannabis on opioid use. All eligible RCTs enrolled patients with chronic cancerrelated pain, and the generalisability to non-cancer chronic pain is uncertain. Specifically, substitution effects of medical cannabis for prescription opioids may also differ between chronic cancer and non-cancer pain; however, lack of variability among studies eligible for our review precluded exploration of this subgroup effect. Studies included in our review administered different formulations of cannabis and cannabinoid products; however, pooled effects of outcomes reported in RCTs showed no important heterogeneity.

A meta-analysis of preclinical studies, ${ }^{17}$ a narrative systematic review, ${ }^{60}$ and several cross-sectional and case studies have reported an apparent reduction in opioid use with addition of cannabis therapy. ${ }^{9}{ }^{1061-65}$ In a national US populationbased survey ${ }^{66}$ of 2774 cannabis users (both medical and non-medical use) $36 \%$ of respondents reported substituting cannabis for prescription opioids (discontinued opioid use). In this survey, the $60 \%$ of participants who identified as medical cannabis users were much more likely to substitute cannabis for prescription drugs than recreational users (OR 4.59; $95 \%$ CI 3.87 to 5.43). Another US survey ${ }^{67}$ that included 841 patients prescribed long-term opioid therapy for chronic pain reported that $61 \%$ used medical cannabis, and $97 \%$ of this subgroup reported coincident reduction of their opioid use. Consistent with these findings, very low certainty evidence from observational studies in our review also suggests that adding medical cannabis allows patients predominantly with chronic non-cancer pain to reduce their use of opioids. Although RCT results do not support reduction in opioid dose by adding medical cannabis for opioids, the evidence is also very low certainty, primarily because investigators instructed patients to maintain their current opioid dose. This is a critical limitation, despite the 2019 National Institute for Health and Care Excellence guideline having concluded that providing medical cannabis for chronic pain does not reduce opioid use on the basis of these trials. ${ }^{68}$ Future trials should randomise chronic pain patients who voluntarily agree to engage in a trial of opioid tapering to receive medical cannabis or placebo and report all patient-important outcomes ${ }^{69}$ Forced opioid tapering is ineffective $^{70}$ and may cause harm. ${ }^{71}$

\section{CONCLUSION}

The opioid-sparing effects of medical cannabis for chronic pain remain uncertain. Based on moderate-to-high certainty evidence, adding medical cannabis to opioid therapy among chronic cancer pain patients had little or no effect on neither pain relief nor sleep disturbance and likely increases the risk of nausea and vomiting. The accompanying BMJ Rapid Recommendation ${ }^{18}$ provides contextualised guidance based on this evidence, as well as three other systematic reviews on benefits, ${ }^{72}$ harms ${ }^{73}$ and patients' values and preferences. ${ }^{74}$

\section{Author affiliations}

${ }^{1}$ Department of Health Research Methods, Evidence, and Impact, McMaster University, Hamilton, Ontario, Canada

${ }^{2}$ The Michael G. DeGroote National Pain Center, McMaster University, Hamilton, Ontario, Canada

${ }^{3}$ Department of Anesthesia, McMaster University, Hamilton, Ontario, Canada ${ }^{4}$ Division of Orthopaedic Surgery, Department of Surgery, McMaster University, Hamilton, Ontario, Canada

${ }^{5}$ Division of of General Internal Medicine, University of Geneva Faculty of Medicine, Geneve, Switzerland

${ }^{6}$ The Chronic Pain Centre of Excellence for Canadian Veterans, Hamilton, Ontario, Canada

${ }^{7}$ The Michael G. DeGroote Centre for Medicinal Cannabis Research, McMaster University, Hamilton, Ontario, Canada

\section{Twitter Jason W Busse @JasonWBusse}

Contributors JWB, AN and GHG conceived and designed the study. RJC performed the literature search. AN, AM, YS, VA and YR selected the studies, extracted the relevant information, and assessed the risk of bias of selected studies. AN synthesised the data. AN wrote the first draft of the paper. AN, JWB, GHG and TA critically revised the manuscript for important intellectual content. AN, JWB, LT, GHG, MB and DNB interpreted the findings. JWB, LT and GHG provided methodological support. All authors reviewed the paper and approved the final version. The corresponding author attests that all listed authors meet authorship criteria and that no others meeting the criteria have been omitted. 
Funding The authors have not declared a specific grant for this research from any funding agency in the public, commercial or not-for-profit sectors.

Competing interests None declared.

Patient consent for publication Not required

Provenance and peer review Not commissioned; externally peer reviewed.

Data availability statement Data are available on reasonable request to the corresponding author at: bussejw@mcmaster.ca.

Supplemental material This content has been supplied by the author(s). It has not been vetted by BMJ Publishing Group Limited (BMJ) and may not have been peer-reviewed. Any opinions or recommendations discussed are solely those of the author(s) and are not endorsed by BMJ. BMJ disclaims all liability and responsibility arising from any reliance placed on the content. Where the content includes any translated material, BMJ does not warrant the accuracy and reliability of the translations (including but not limited to local regulations, clinical guidelines, terminology, drug names and drug dosages), and is not responsible for any error and/or omissions arising from translation and adaptation or otherwise.

Open access This is an open access article distributed in accordance with the Creative Commons Attribution Non Commercial (CC BY-NC 4.0) license, which permits others to distribute, remix, adapt, build upon this work non-commercially, and license their derivative works on different terms, provided the original work is properly cited, appropriate credit is given, any changes made indicated, and the use is non-commercial. See: http://creativecommons.org/licenses/by-nc/4.0/.

ORCID iDs

Lehana Thabane http://orcid.org/0000-0003-0355-9734

Jason W Busse http://orcid.org/0000-0002-0178-8712

\section{REFERENCES}

1 Schopflocher D, Taenzer P, Jovey R. The prevalence of chronic pain in Canada. Pain Res Manag 2011;16:445-50.

2 Schappert SM, Burt CW. Ambulatory care visits to physician offices, hospital outpatient departments, and emergency departments: United States, 2001-02. Vital Health Stat 13 2006;159:1-66.

3 International Narcotics Control Board. Narcotic drugs: estimated world requirements for 2019. Vienna: United Nations. Available: https://www.incb.org/documents/Narcotic-Drugs/TechnicalPublications/2018/INCB-Narcotics_Drugs_Technical_Publication_ 2018.pdf [Accessed 2 Nov 2020].

4 Busse JW, Wang L, Kamaleldin M, et al. Opioids for chronic noncancer pain: a systematic review and meta-analysis. JAMA 2018;320:2448-60.

5 Gomes T, Greaves S, Martins D. Latest trends in Opioid-Related deaths in Ontario: 1991 to 2015. Toronto: Ontario Drug Policy Research Network, 2017.

6 Busse JW, Craigie S, Juurlink DN, et al. Guideline for opioid therapy and chronic noncancer pain. CMAJ 2017;189:E659-66.

7 Gomes T, Mamdani MM, Paterson JM, et al. Trends in high-dose opioid prescribing in Canada. Can Fam Physician 2014;60:826-32.

8 Bedson J, Chen Y, Ashworth J, et al. Risk of adverse events in patients prescribed long-term opioids: a cohort study in the UK clinical practice research Datalink. Eur J Pain 2019;23:908-22.

9 Gwira Baumblatt JA, Wiedeman C, Dunn JR, et al. High-Risk use by patients prescribed opioids for pain and its role in overdose deaths. JAMA Intern Med 2014;174:796-801.

10 Bohnert ASB, Logan JE, Ganoczy D, et al. A detailed exploration into the association of prescribed opioid dosage and overdose deaths among patients with chronic pain. Med Care 2016;54:435-41.

11 Attal N, Mazaltarine G, Perrouin-Verbe B, et al. Chronic neuropathic pain management in spinal cord injury patients. What is the efficacy of pharmacological treatments with a general mode of administration? (oral, transdermal, intravenous). Ann Phys Rehabil Med 2009;52:124-41.

12 Livingston MD, Barnett TE, Delcher C. And Opioid-Related deaths in Colorado, 2000-2015. Am J Public Health 2017;107:1827-9.

13 Bradford AC, Bradford WD. Medical marijuana laws reduce prescription medication use in Medicare Part D. Health Aff 2016;35:1230-6.

14 Bachhuber MA, Saloner B, Cunningham CO, et al. Medical cannabis laws and opioid analgesic overdose mortality in the United States, 1999-2010. JAMA Intern Med 2014;174:1668-73.

15 Boehnke KF, Litinas E, Clauw DJ. Medical cannabis use is associated with decreased opiate medication use in a retrospective cross-sectional survey of patients with chronic pain. J Pain 2016;17:739-44.

16 Piper BJ, DeKeuster RM, Beals ML, et al. Substitution of medical cannabis for pharmaceutical agents for pain, anxiety, and sleep. $J$ Psychopharmacol 2017;31:569-75.

17 Nielsen S, Sabioni P, Trigo JM, et al. Opioid-Sparing effect of cannabinoids: a systematic review and meta-analysis. Neuropsychopharmacology 2017;42:1752-65.

18 Busse JW, Vankrunkelsven P, Zeng L. Medical cannabis for chronic pain: a clinical practice guideline. BMJ2020.

19 Stroup DF, Berlin JA, Morton SC, et al. Meta-Analysis of observational studies in epidemiology: a proposal for reporting. meta-analysis of observational studies in epidemiology (moose) group. JAMA 2000;283:2008-12.

20 Liberati A, Altman DG, Tetzlaff J, et al. The PRISMA statement for reporting systematic reviews and meta-analyses of studies that evaluate healthcare interventions: explanation and elaboration. BMJ 2009;339:b2700.

21 Classification of chronic pain. Classification of chronic pain. descriptions of chronic pain syndromes and definitions of pain terms. prepared by the International association for the study of pain Subcommittee on taxonomy. Pain Suppl 1986;3:S1-226.

22 Lintzeris N, Driels J, Elias N, et al. Medicinal cannabis in Australia, 2016: the cannabis as medicine survey (CAMS-16). Med J Aust 2018;209:211-6.

23 EISohly MA, Ross SA, Mehmedic Z, et al. Potency trends of delta9THC and other cannabinoids in confiscated marijuana from 1980 1997. J Forensic Sci 2000;45:14636J-30.

24 Reeves BC, Deeks JJ, Higgins JPT. Chapter 24: Including nonrandomized studies on intervention effects. In: Higgins JPT TJ, Chandler J, Cumpston M, et al, eds. Editor: cochrane Handbook for systematic reviews of interventions version 6.1, 2020. www.training. cochrane.org/handbook;

25 Dworkin $\mathrm{RH}$, Turk DC, Farrar JT, et al. Core outcome measures for chronic pain clinical trials: IMMPACT recommendations. Pain 2005;113:9-19.

26 Goshua A, Craigie S, Guyatt GH, et al. Patient values and preferences regarding opioids for chronic noncancer pain: a systematic review. Pain Med 2018;19:2469-80.

27 Akl EA, Sun X, Busse JW, et al. Specific instructions for estimating unclearly reported blinding status in randomized trials were reliable and valid. J Clin Epidemiol 2012;65:262-7.

28 Higgins JPT, Altman DG, Gøtzsche PC, et al. The Cochrane collaboration's tool for assessing risk of bias in randomised trials. BMJ 2011;343:d5928.

29 Tool to Assess Risk of Bias. Clarity group at McMaster University, 2020. Available: www.evidencepartners.com/resources/ methodological-resources/: Evidence partner [Accessed 4 Nov 2020].

30 Landis JR, Koch GG. The measurement of observer agreement for categorical data. Biometrics 1977;33:159-74.

31 Farrar JT, Young JP, LaMoreaux L, et al. Clinical importance of changes in chronic pain intensity measured on an 11-point numerical pain rating scale. Pain 2001;94:149-58.

32 Zisapel N, Nir T. Determination of the minimal clinically significant difference on a patient visual analog sleep quality scale. J Sleep Res 2003;12:291-8.

33 DerSimonian R, Laird N. Meta-Analysis in clinical trials. Control Clin Trials 1986;7:177-88.

34 Wan X, Wang W, Liu J, et al. Estimating the sample mean and standard deviation from the sample size, median, range and/or interquartile range. BMC Med Res Methodol 2014;14:135.

35 Ma J, Liu W, Hunter A, et al. Performing meta-analysis with incomplete statistical information in clinical trials. BMC Med Res Methodol 2008;8:56.

36 Rücker G, Cates CJ, Schwarzer G. Methods for including information from multi-arm trials in pairwise meta-analysis. Res Synth Methods 2017;8:392-403.

37 Rücker G, Schwarzer G, Carpenter JR, et al. Undue reliance on I(2) in assessing heterogeneity may mislead. BMC Med Res Methodol 2008;8:79.

38 Guyatt GH, Oxman AD, Vist GE, et al. Grade: an emerging consensus on rating quality of evidence and strength of recommendations. BMJ 2008;336:924-6.

39 Higgins JPT, Thomas J, Chandler J, eds. Cochrane Handbook for Systematic Reviews of Interventions version 6.0 (updated July 2019). Cochrane, 2019. www.training.cochrane.org/handbook

40 Guyatt GH, Oxman AD, Kunz R, et al. GRADE guidelines: 8. Rating the quality of evidence--indirectness. J Clin Epidemio 2011;64:1303-10. 
41 Guyatt GH, Oxman AD, Sultan S, et al. Grade guidelines: 9. rating up the quality of evidence. J Clin Epidemiol 2011;64:1311-6.

42 Egger M, Davey Smith G, Schneider M, et al. Bias in meta-analysis detected by a simple, graphical test. BMJ 1997;315:629-34.

43 Fallon MT, Albert Lux E, McQuade R, et al. Sativex oromucosal spray as adjunctive therapy in advanced cancer patients with chronic pain unalleviated by optimized opioid therapy: two doubleblind, randomized, placebo-controlled phase 3 studies. Br J Pain 2017;11:119-33.

44 Johnson JR, Burnell-Nugent M, Lossignol D, et al. Multicenter, double-blind, randomized, placebo-controlled, parallel-group study of the efficacy, safety, and tolerability of THC:CBD extract and THC extract in patients with intractable cancer-related pain. $J$ Pain Symptom Manage 2010;39:167-79.

45 Lichtman AH, Lux EA, McQuade R, et al. Results of a double-blind, randomized, placebo-controlled study of Nabiximols Oromucosal spray as an adjunctive therapy in advanced cancer patients with chronic uncontrolled pain. J Pain Symptom Manage 2018;55:179-88.

46 Portenoy RK, Ganae-Motan ED, Allende S, et al. Nabiximols for opioid-treated cancer patients with poorly-controlled chronic pain: a randomized, placebo-controlled, graded-dose trial. $J$ Pain 2012;13:438-49.

47 Barlowe TS, Koliani-Pace JL, Smith KD, et al. Effects of medical cannabis on use of opioids and hospital visits by patients with painful chronic pancreatitis. Clin Gastroenterol Hepatol 2019;17:2608-9.

48 Bellnier T, Brown GW, Ortega TR. Preliminary evaluation of the efficacy, safety, and costs associated with the treatment of chronic pain with medical cannabis. Ment Health Clin 2018;8:110-5.

49 Capano A, Weaver R, Burkman E. Evaluation of the effects of CBD hemp extract on opioid use and quality of life indicators in chronic pain patients: a prospective cohort study. Postgrad Med 2020;132:56-61.

50 Haroutounian S, Ratz Y, Ginosar Y, et al. The effect of medicinal cannabis on pain and quality-of-life outcomes in chronic pain: a prospective open-label study. Clin J Pain 2016;32:1036-43.

51 Maida V, Ennis M, Irani S, et al. Adjunctive nabilone in cancer pain and symptom management: a prospective observational study using propensity scoring. J Support Oncol 2008;6:119-24.

52 Narang S, Gibson D, Wasan AD, et al. Efficacy of dronabinol as an adjuvant treatment for chronic pain patients on opioid therapy. $J$ Pain 2008;9:254-64.

53 O'Connell M, Sandgren M, Frantzen L, et al. Medical cannabis: effects on opioid and benzodiazepine requirements for pain control. Ann Pharmacother 2019;53:1081-6.

54 Pritchard ER, Dayer L, Belz J, et al. Effect of cannabis on opioid use in patients with cancer receiving palliative care. J Am Pharm Assoc 2020;60:244-7.

55 Pawasarat IM, Schultz EM, Frisby JC, et al. The efficacy of medical marijuana in the treatment of cancer-related pain. $J$ Palliat Med 2020;23:809-16.

56 Rod K. A Pilot Study of a Medical Cannabis - Opioid Reduction Program. AJPN 2019;7:74.

57 Takakuwa KM, Hergenrather JY, Shofer FS, et al. The impact of medical cannabis on intermittent and chronic opioid users with back pain: how cannabis diminished prescription opioid usage. Cannabis Cannabinoid Res 2020;5:263-70.
58 Vigil JM, Stith SS, Adams IM, et al. Associations between medical cannabis and prescription opioid use in chronic pain patients: a preliminary cohort study. PLoS One 2017;12:e0187795.

59 Yassin M, Oron A, Robinson D. Effect of adding medical cannabis to analgesic treatment in patients with low back pain related to fibromyalgia: an observational cross-over single centre study. Clin Exp Rheumatol 2019;37 Suppl 116:13-20.

60 Okusanya BO, Asaolu IO, Ehiri JE, et al. Medical cannabis for the reduction of opioid dosage in the treatment of non-cancer chronic pain: a systematic review. Syst Rev 2020;9:167.

61 Zaller N, Topletz A, Frater S, et al. Profiles of medicinal cannabis patients attending compassion centers in Rhode island. $J$ Psychoactive Drugs 2015;47:18-23.

62 Hazekamp A, Ware MA, Muller-Vahl KR, et al. The medicinal use of cannabis and Cannabinoids-An international crosssectional survey on administration forms. J Psychoactive Drugs 2013;45:199-210.

63 Lucas P, Walsh Z, Crosby K, et al. Substituting cannabis for prescription drugs, alcohol and other substances among medical cannabis patients: the impact of contextual factors. Drug Alcohol Rev 2016;35:326-33.

64 Cooper ZD, Bedi G, Ramesh D, et al. Impact of co-administration of oxycodone and smoked cannabis on analgesia and abuse liability. Neuropsychopharmacology 2018;43:2046-55.

65 Ishida JH, Wong PO, Cohen BE, et al. Substitution of marijuana for opioids in a national survey of US adults. PLOS One 2019;14:e0222577.

66 Corroon JM, Mischley LK, Sexton M. Cannabis as a substitute for prescription drugs - a cross-sectional study. J Pain Res 2017;10:989-98.

67 Reiman A, Welty M, Solomon P. Cannabis as a substitute for OpioidBased pain medication: patient self-report. Cannabis Cannabinoid Res 2017;2:160-6.

68 The National Institute for health and care excellence (NICE) cannabisbased medicinal products (NG144), 2019. Available: https://www. nice.org.uk/guidance/ng144/chapter/Recommendations\#chronicpain [Accessed 21 May 2021].

69 Mulla SM, Maqbool A, Sivananthan L, et al. Reporting of IMMPACTrecommended core outcome domains among trials assessing opioids for chronic non-cancer pain. Pain 2015;156:1615-9.

70 Frank JW, Carey E, Nolan C, et al. Association between opioid dose reduction against patients' wishes and change in pain severity. $J$ Gen Intern Med 2020;35:910-7.

71 Busse JW, Juurlink D, Guyatt GH. Addressing the limitations of the CDC guideline for prescribing opioids for chronic noncancer pain. CMAJ 2016;188:1210-1.

72 Wang L, Hong PJ, May C. Medical cannabis or cannabinoids for chronic pain: a systematic review and meta-analysis of randomized clinical trials. BMJ 2021.

73 Zeraatkar D, Cooper MA, Agarwal A. Long-Term and serious harms of medical cannabis or cannabinoids for chronic pain: a systematic review of non-randomized studies. BMJ Open 2021.

74 Zeng L, Lytvyn L, Wang X. Values and preferences towards medical cannabis or cannabinoids among patients with chronic pain: a mixed methods systematic review. BMJ Open 2021. 